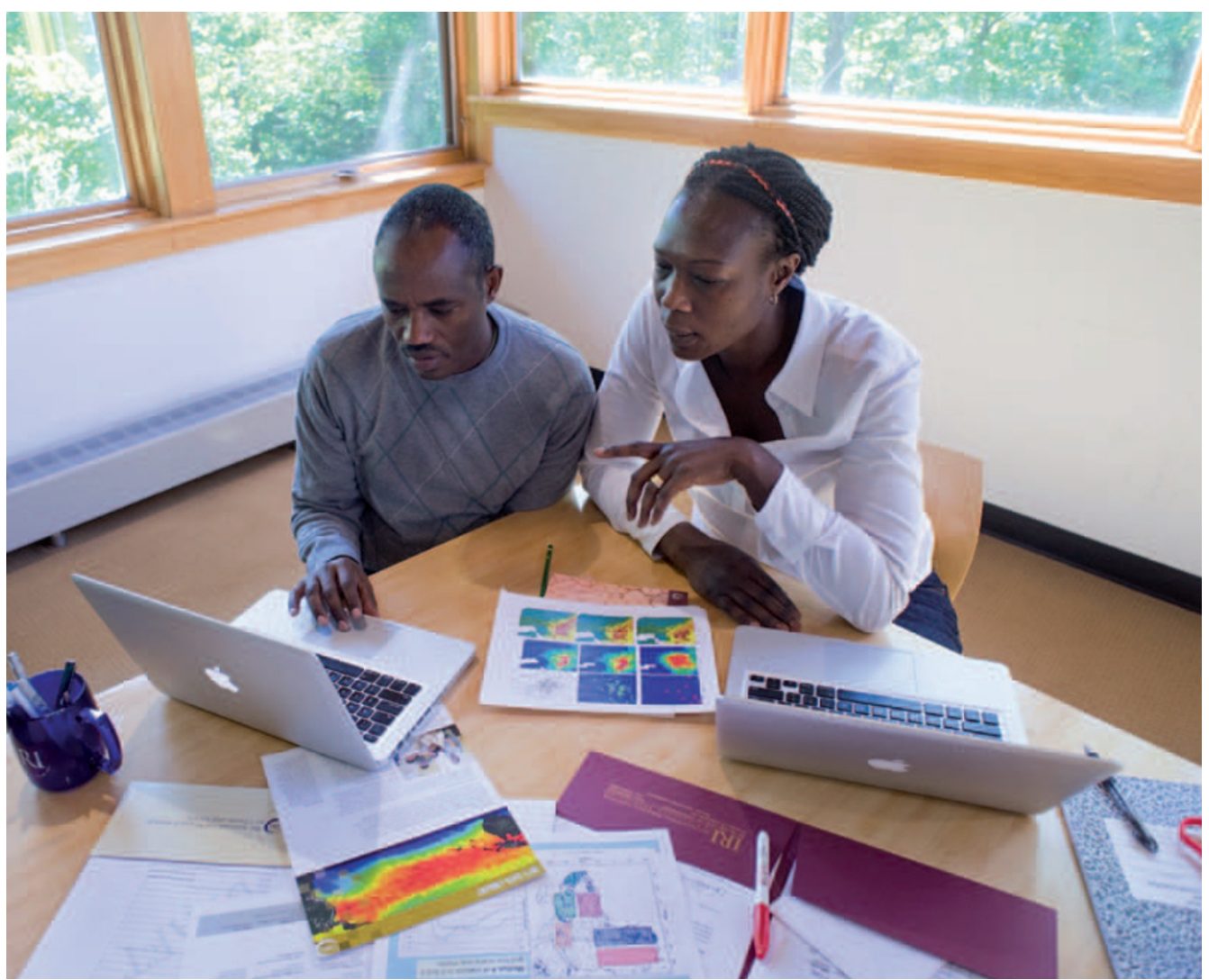

Ethiopian meteorologist Tufa Dinku working with Kenyan epidemiologist Judy Omumbo at Columbia University, New York.

\title{
Africa needs climate data to fight disease
}

\section{Madeleine C. Thomson and colleagues call on climate and health researchers, policy-makers and practitioners to work together to tackle infectious diseases.}

\section{$\mathrm{C}$} limate variability and change are a major concern for public health in Africa. The livelihoods of hundreds of millions of people there are dependent on rain-fed agriculture and seasonal water resources. Poor rural communities also suffer from undernutrition and bear the greatest burden of infectious diseases and natural disasters while having the least access to public-health services. Many of Africa's most important cities are on the coast and at risk of sea level rise. Without adequate infrastructure they are vulnerable to poor sanitation during floods and shortages of drinking water and loss of hydroelectric power during droughts. Rising temperatures, air pollutants and dust threaten to increase heat stress and respiratory disease.

The Fourth Assessment Report of the
Intergovernmental Panel on Climate Change predicts increased rainfall in eastern Africa over the coming century ${ }^{1}$. Yet there has been a region-wide drought over the past ten years ${ }^{2}$. Policy-makers want to know whether to prepare, short-term, for floods or droughts. They also need to know if the recent drying has aided malaria-control interventions in the region. But answering such questions is tricky.

Climate information is not readily available, so is rarely incorporated into development decisions. At the same time, few public-health institutions or practitioners are equipped to understand or manage the effects of a changing climate ${ }^{3}$, despite major advances in recent years in alerting the health community to its risks.

A dramatic improvement is needed in the availability of relevant and reliable climate data and services, particularly in Africa, where vulnerability to climate is is so high. Information - such as historical observations of temperature, ten-day satellite estimates of rainfall, the predicted start date of the rainy season or the likelihood of extreme temperatures in the coming season - should inform the management of all diseases sensitive to climate. These include: malaria, leishmaniasis, acute respiratory infections, intestinal helminths and diarrhoeal diseases. This information could also contribute to food security by providing, for example, early warning for agricultural and livestock pests and diseases.

The following must be put in place within the next decade: new partnerships between the public-health community and national 
meteorological agencies, space agencies and researchers; a governance structure that ensures data sharing between public and private agencies; a funding model that builds open-access climate databases; climate scientists focused on the delivery of quality products, tailored to user needs; health professionals trained to demand and use climate information; and evidence of the value of all this, relative to alternative investments in health.

\section{TRANSFORMATIONAL POWER}

Good climate information, if freely available, could transform the way in which the health community does business. For example, it could improve health calendars for seasonal diseases. It could lead to better timing of the distribution of bed nets, local public awareness campaigns, and drugs with a short shelf life. Health professionals could be better prepared for the diseases that follow floods and storms, such as leptospirosis and cholera. It would also enable better mapping of regions and populations vulnerable to emerging health problems such as meningococcal meningitis epidemics, which favour the hot, dry and dusty Sahel, a region that may be expanding owing to climate and environmental change. On longer time scales, researchers could probe the drivers and potential recurrence of major climatic events, such as the devastating Ethiopian drought of 1984-85 (immortalized in the Western psyche by Bob Geldof's Band Aid).

On 4-6 April, in Addis Ababa, professionals - including policy-makers, practitioners, researchers, donors and the media - interested in using climate science to inform public-health decisions will meet at the Climate and Health in Africa: 10 Years On conference. Participants must reflect on the slow progress since the groundbreaking Climate Prediction and Disease/Health in Africa workshop in Bamako, Mali, in 1999. There, climate scientists committed to working directly with health practitioners and researchers. Participants must now agree a road map for concrete action over the next decade.

The long-running debate on the likely effect of a warming climate on malaria in East Africa illustrates the problem. Over the past decade, numerous studies, with contradictory results, have attempted to explain the observed rise in malaria incidence in the western Kenyan highlands. For instance, peak monthly cases of malaria increased eightfold from the 1970s to the 2000s at the hospital that serves the Brooke Bond Farms (now Unilever Tea Kenya), tea estates near Kericho (with some tailing off in recent years $)^{4}$.

Researchers who found no evidence of significant warming at this site during the same period concluded that only non-climatic factors (for example drug resistance, and local environmental change) could be driving the increased malaria incidence ${ }^{5}$. Those who found evidence of warming proposed that climate must play a part ${ }^{4}$. These conflicting results fuelled a heated and polarizing debate ${ }^{6}$ in the malaria and climate-change literature (including this journal) and the media. The spat paralysed the discussion of climate and health at the highest policy level.

The limited access to daily observations of surface air temperature from meteorological stations, in quality-controlled, long, time series has constrained studies. They have relied heavily on short time series, used data of poor quality or ignored local ground observations in favour of spatially interpolated global data sets that could not provide meaningful results at local scale.

The value of the data held by national meteorological and hydrological services was made evident through a recent analysis of 30 years (1979-2009) of daily temperature and rainfall data from the Kericho meteorological station managed by the Kenya Meteorological Department; the data conform to World Meteorological Organization standards. The study ${ }^{7}$ (the authors of which include S.J.C. and M.C.T.)

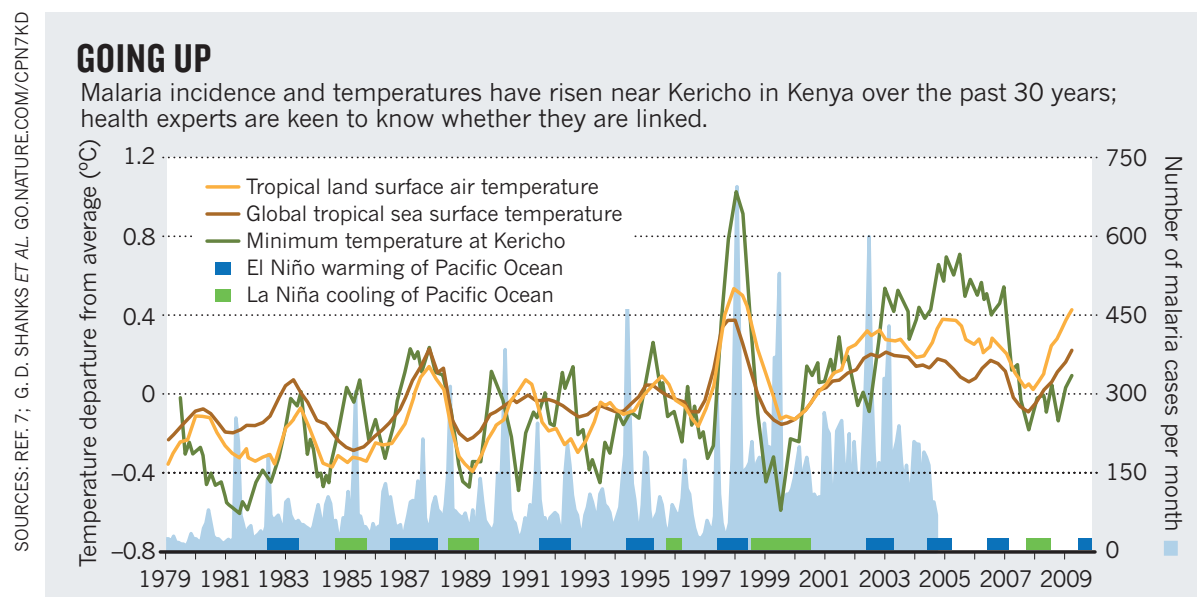

establishes that minimum and maximum temperatures, at this much-studied site, have been rising by about $0.2^{\circ} \mathrm{C}$ a decade over the past 30 years. Furthermore, the study demonstrated the association between local temperatures in Kericho and sea surface and land surface temperature in the tropics - indicating the close relationship of the local Kericho climate to the larger climate system (see 'Going up').

Only now can researchers start to look properly for direct links between malaria incidence and climate variability and change in the area. We cannot yet say that warming helped the observed increase in malaria although there is good reason to believe that it might ${ }^{4}$. But we can say that climate should not be dismissed as a potential driver in the area. The key concern is that, if there is a link, increased warming in the East African highlands may expose a largely naive population to malaria with devastating consequences.

That it took a decade to establish a robust analysis of climate trends in Kericho, a focus of so much controversy, points to a broader disconnect between those who need climate information and those who produce it. In the 1980s, African meteorological agencies were encouraged to sell their data to raise revenue to maintain their networks of meteorological stations. The agencies' services have understandably prioritized their primary client, the airline industry. Access for non-commercial purposes, including for malaria research, has been constrained by poor collaboration and high data fees, among other factors.

Instead, funding models are needed that recognize climate data as a resource for development - a classic public good that increases in value the more times the data are used.

\section{ETHIOPIAN PROMISE}

The potential benefits of getting it right are considerable. Ethiopia, a country particularly vulnerable to the vagaries of climate, provides a promising example of what might be achieved. A new climate database there will draw on more than 600 national meteorological stations merged with 30 years of 10-day satellite data collected for rainfall monitoring. Generally fewer than 20 stations are available internationally via the Global Telecommunications System - the source of ground observations used in most available rainfall monitoring products. Ethiopia's National Meteorological Agency is getting technical support from the International Research Institute for Climate and Society (the IRI - where M.C.T., S.J.C. and S.E.Z. work) and the Tropical Applications of Meteorology using Satellite data (TAMSAT) research group at the University of Reading, UK. The effort is funded by Google.org, the philanthropic arm of Google, and lent 
technical support by the IRI through a cooperative agreement between Columbia University in New York (where the IRI is located) and the US National Oceanic and Atmospheric Administration.

This high-quality database will be used to create free-access climate reports tailored to the needs of the Ethiopian health community ${ }^{8}$ and other development sectors, such as agriculture and water resources. It will also be used to improve the assessment of climate-sensitive interventions such as the indoor spraying programmes supported through the Roll Back Malaria initiative. One would expect such measures to work when conditions are least favourable to malaria transmission, for example, during a drought. The database will also help the development of local, seasonal climate forecasts - of unusually wet or dry conditions, say.

The Ethiopian climate database, the first of its kind, provides an opportunity to establish the value of climate information to improving health. Now that the system has been developed, the process can be more readily repeated in other countries. Doing so will build capacity where it is needed most - in the national meteorological agencies, regional climate centres and local universities ${ }^{9}$.

\section{BETTER TOGETHER}

Health professionals need skills to understand and interpret climate data, and to request new types of information or services. They also need to develop mechanisms to incorporate this information into current epidemiological approaches in a cost-effective manner.

One way forward is to target professional training and research in schools of public health. For instance, health-surveillance communities routinely monitor and prevent outbreaks and epidemics, through the analysis of current and historic epidemiological data. Where such events are climate-sensitive (for example Rift Valley fever epidemics) seasonal forecasts, meteorological information and satellite data could help map, monitor or anticipate changes in risk.

The Climate Information for Public Health Action Network, led by the IRI, and its associated training are steps in the right direction. The curriculum ${ }^{10}$ enables climate and health experts to work together on common data sets and analyses, focusing the results on the needs of decision-makers. As a result, the African Field Epidemiology Network is exploring how climate information might be used in training for outbreak investigation.

The Climate for Development in Africa project was launched in October 2010. This is a joint initiative of the African Union Commission, the United Nations
Economic Commission for Africa and the African Development Bank. The project has a start-up fund of US\$136 million and a clear mandate from African heads of state to help fill key gaps in policy, practice, services and data across the continent. It is a daunting but necessary task. To achieve its development targets, the initiative will need to respond directly to the needs of climate-sensitive sectors, including health.

The global health community has worked for decades to get the resources necessary for effective control of diseases that affect poor people globally, especially malaria. Some people understandably fear that hard-won gains in political and financial support may be diluted, or worse derailed, by the climatechange agenda - especially in such aid-slashing times. But 'turf' anxieties are no reason for poor science. True interdisciplinarity requires more than fair-weather friends.

Climate is most important as a driver of infectious disease where and when control efforts are weak and societies are poor. Climate information can help to put resources where they are needed most. It is an essential additional layer of data for disease prevention, control and elimination.

History tells us that success against a single infectious disease such as malaria may be short lived if we are over-reliant on too few controls and lose a broad understanding of the disease. Rather than pursuing parallel agendas, the climate and health communities must work together now to deliver measurable health improvements in Africa in the next ten years and beyond.

Madeleine C. Thomson, Stephen J. Connor and Stephen E. Zebiak are at the International Research Institute for Climate and Society, the Earth Institute, Columbia University, Palisades, New York 10964, USA. Michel Jancloes is at the Health and Climate Foundation, Washington DC 20005, USA. Abere Mihretie is at the Anti-Malaria Association, Addis Ababa, Ethiopia. e-mail:mthomson@iri.columbia.edu;

1. Parry, M. L. et al. (eds) Climate Change 2007: Impacts, Adaptation and Vulnerability. Contribution of Working Group II to the Fourth Assessment Report of the Intergovernmental Panel on Climate Change (Cambridge Univ. Press, 2007).

2. Park Williams, A. \& Funk, C. Clim. Dynam. doi:10.1007/s00382-010-0984-y (2011).

3. Connor, S. J. et al. Proc. Environ. Sci. 1, 27-36 (2010).

4. Alonso, D., Bouma, M. J. \& Pascual, M. Proc. R. Soc. B doi:10.1098/rspb.2010.2020 (2010).

5. Hay, S. I. et al. Trends Parasitol. 18, 530-534 (2002).

6. Reiter, P. Rev. Sci. Tech. OIE 27, 383-398 (2008).

7. Omumbo, J. A., Lyon, B., Waweru, S. M., Connor, S. J. \& Thomson, M. C. Malaria J. 10, 12 (2011).

8. Ghebreyesus, T. A. et al. WMO Bulletin 57, 256-261 (2008).

9. Dinku, T. Clim. Dev. 2, 9-13 (2010).

10. Cibrelus, L. \& Mantilla, G. Climate Information for Public Health: A Curriculum for Best Practices Putting Principles to Work. IRI Technical Report 163 (2010); available at go.nature.com/3rg2eq 